\title{
PENGARUH PENGENDALIAN INTERN, KEPATUHAN, KOMPENSASI \\ MANAJEMEN TERHADAP PERILAKU ETIS KARYAWAN \\ (STUDI KASUS : PADA PERUSAHAAN DISTRIBUTOR \\ FARMASI PT ENSEVAL PUTERA MEGATRADING TBK PUSAT)
}

\author{
Tagor Darius Sidauruk, SE.,M.Si \\ dan \\ Suci Lestari \\ FAKULTAS EKONOMI AKUNTANSI \\ UNIVERSITAS SATYA NEGARA INDONESIA
}

\begin{abstract}
This study aims to determine the effect of internal control, compliance, compensation management to ethical behavior of employees Center of PT Enseval Putera Megatrading Tbk. This study uses primary data obtained from questionnaires to the respondents. The sampling method used is purposive sampling and data that meet the criteria are as many as 60 samples. Multiple linear analysis is a technique of data analysis used in this study. The results obtained showed that partial internal control does not affect the ethical behavior of employees, compliance affect the ethical behavior of employees and management compensation does not affect the ethical behavior does not affect the ethical behavior of employees Center of PT Enseval Putera MegatradingTbk.

Keywords : Internal Control, Compliance, Compensation Management, Ethical Behavior
\end{abstract}

\section{PENDAHULUAN}

Masalah sumber daya manusia masih menjadi sorotan dan tumpuan bagi perusahaan untuk tetap bertahan di era globalisasi. Sumber daya manusia mempunyai peran utama dalam setiap kegiatan perusahaan, walaupun didukung dengan sarana dan prasarana serta sumber dana yang berlebihan, tetapi tanpa sumber daya manusia yang andal kegiatan perusahaan tidak akan terselesaikan dengan baik. Hal ini menunjukan bahwa sumber daya manusia merupakan kunci pokok yang harus diperhatikan dengan segala kebutuhannya.

Melihat pentingnya sumber daya manusia, ada banyak karyawan yang bekerja dengan sungguh-sungguh atau berperilaku baik (etis) dalam suatu perusahaan, tetapi ada juga yang bekerja di luar kontrol sehingga dapat membawa karyawan kearah perilaku yang tidak baik atau perilaku tidak etis.Seperti halnya pada PT Enseval Putera Megatrading sering sekali terjadi tindakan yang tidak etis yang dilakukan oleh karyawan pada cabang seperti pelarian uang setoran yang dilakukan oleh karyawan, manipulasi data keuangan kasir yang berujung pada kerugian yang harus dialami perusahaan, manipulasi data kehadiran karyawan. Perilaku tidak etis ini muncul karena lemahnya sistem pengendalian yang dilakukan manajemen. Oleh karena itu, dibutuhkan sistem pengendalian intern 
bagi suatu organisasi/ perusahaan agar sumber daya manusia yang ada didalam suatu organisasi dapat berperilaku etis, Pengendalian intern merupakan suatu cara untuk mengarahkan, mengawasi, dan mengukur sumber daya suatu organisasi.

Selain pengendalian internal faktor yang dapat mempengaruhi perilaku etis karyawan adalah kepatuhan. Menurut (Agoes, 2009:49) kepatuhan sebagai pemeriksaan untuk mengetahui apakah prosedur dan aturan yang telah ditetapkan otoritas berwenang sudah ditaati oleh personil di organisasi tersebut.

Faktor lainnya yang dapat mempengaruhi perilaku etis karyawan adalah masalah Kompensasi Manajemen.Kompensasi merupakan balas jasa yang diberikan oleh organisasi/perusahaan kepada karyawan, yang dapat bersifat finansial maupun non finansial, pada periode yang tetap.

Adanya indikator permasalah diatas mendorong peneliti untuk melakukan penelitian dengan mengambil judul "Pengaruh Pengendalian Intern, Kepatuhan dan Kompensasi Manajemen terhadap Perilaku Etis Karyawan" (Studi Kasus: pada Perusahaan Distributor Farmasi PT Enseval Putera Megatrading Tbk Pusat).

Pengendalian internal merupakan suatu sistem yang meliputi stuktur organisasi beserta semua mekanisme dan ukuran-ukuran yang dipatuhi bersama untuk menjaga seluruh harta kekayaan organisasi dari berbagai arah.Hasil penelitian Arifiyani (2012) menyebutkan variabel pengendalian intern berpengaruh positif dan signifikan pada perilaku etis karyawan. Berdasarkan penjelasan diatas dapat dikembangkan hipotesis penelitian sebagai berikut:

H1 : Pengendalian Intern berpengaruh pada perilaku etis karyawan PT Enseval Putera Megatrading Tbk Pusat

Kepatuhan secara etimologis merupakan suatu keadaan tertentu dimana orang-orang yang tergabung dalam organisasi tunduk pada peraturan-peraturan yang ada dengan rasa senang hati. Hasil penelitian Arifiyani (2012) menyebutkan variabel kepatuhan berpengaruh positif dan signifikan pada perilaku etis karyawan. Berdasarkan penjelasan diatas dapat dikembangkan hipotesis penelitian sebagai berikut:

H2 : Kepatuhan berpengaruh pada perilaku etis karyawan PT Enseval Putera Megatrading Tbk Pusat

Kompensasi dapat didefinisikan sebagai setiap bentuk penghargaan yang diberikan kepada karyawan sebagai balas jasa atas kontribusi yang mereka berikan kepada organisasi. Hasil penelitian Arifiyani (2012) menyebutkan variabel kompensasi manajemen berpengaruh positif dan signifikan pada perilaku etis karyawan. 
Berdasarkan penjelasan diatas dapat dikembangkan hipotesis penelitian sebagai berikut:

H3 : Kompensasi manajemen berpengaruh pada perilaku etis karyawan PT

Enseval Putera Megatrading Tbk Pusat

\section{METODE PENELITIAN}

Penelitian dilakukan pada PT Enseval Putera Megatrading Tbk Pusat yang berlokasi di Jalan Pulo Lentut No 10. Objek penelitian mengenai pengaruh pengendalian intern, kepatuhan, kompensasi manajemen terhadap perilaku etis karyawan PT Enseval Putera Megatrading Tbk Pusat.

Variabel terikat penelitian ini adalah perilaku etis dengan indikator budaya organisasi, kondisi politik, perekonomian global. Variabel bebas dari penelitian ini anatara lain pengendalian intern, kepatuhan, dan kompensasi manajemen. Pengandalian intern diukur dengan menggunakan tiga indikator antara lain reabilitas pelaporan keuangan, ketaatan terhadap hukum dan peraturan, efisiensi dan efektivitas organisasi. kepatuhan diukur dengan menggunakan dua indikator antara lain kelengkapan transaksi dan adanya peraturan. Kompensasi manajemen diukur dengan menggunakan empat indikator antara lain gaji, upah, insentif, dan tunjangan.

Penelitian ini menggunakan data primer untuk mengukur variabel bebas (pengendalian intern, kepatuhan, kompensasi manajemen) dan variabel terikat (perilaku etis) yang diambil dari individu dari hasil pengisian kuisioner.

Seluruh karyawan PT Enseval Putera Megatrading Tbk Pusat merupakan populasi dalam penelitian ini. Metode penentuan sampel menggunkan purposive sampling dengan karakteristik reponden yang terkait berwenang dalam pembentukan dan pengawasan SOP. Dan jumlah sampel yang memenuhi kriteria sebanyak 60 responden.Pengumpulan data dengan menggunakan kuisioner yang berisi pertanyaan-pertanyaan yang dijawab langsung oleh responden.

Uji reliabilitas dan uji validitas digunakan karena penelitian ini menggunakan kuisioner. Uji asumsi klasik yang meliputi uji normalitas, multikolinearitas, dan heteroskedastisitas dilakukan agar mengetahui seluruh variabel yang digunakan memenuhi syarat untuk dilanjutkan ke analisis regresi linear berganda. 


\section{HASIL DAN PEMBAHASAN}

Tabel menunjukkan hasil uji reliabilitas dari seluruh variabel yang digunakan pada penelitian ini memenuhi syarat reliabilitas, seperti berikut.

Tabel

Hasil Uji Reliablitas

\begin{tabular}{|c|l|c|}
\hline No. & \multicolumn{1}{|c|}{ Variabel } & $\begin{array}{c}\text { Cronbach's } \\
\text { Alpha }\end{array}$ \\
\hline 1 & Perilaku Etis (Y) & 0,751 \\
2 & Pengendalian Intern (X1) & 0,817 \\
3 & Kepatuhan (X2) & 0,715 \\
4 & Kompensasi Manajemen (X3) & 0,754 \\
\hline
\end{tabular}

sumber : Data Diolah, 2016

Tabel menjelaskan semua instrumen yang digunakan adalah valid atau layak digunakan. Hasil uji validitas dapat dilihat pada Tabel sebagai berikut:

\section{Tabel}

\section{Hasil Uji Validitas}

\begin{tabular}{|c|c|c|c|}
\hline No. & Variabel & Item Pertanyaan & $\begin{array}{c}\text { Koefisien } \\
\text { Korelasi (R) }\end{array}$ \\
\hline \multirow[t]{8}{*}{1} & Perilaku Etis (Y) & Y1 & 0,477 \\
\hline & & Y2 & 0,720 \\
\hline & & Y3 & 0,721 \\
\hline & & Y4 & 0,644 \\
\hline & & Y5 & 0,532 \\
\hline & & Y6 & 0,570 \\
\hline & & Y7 & 0,567 \\
\hline & & Y8 & 0,606 \\
\hline \multirow[t]{4}{*}{2} & Pengendalian Inter (X1) & $\mathrm{X} 1.1$ & 0,778 \\
\hline & & $\mathrm{X} 1.2$ & 0,591 \\
\hline & & $\mathrm{X} 1.3$ & 0,658 \\
\hline & & $\mathrm{X} 1.4$ & 0,691 \\
\hline
\end{tabular}




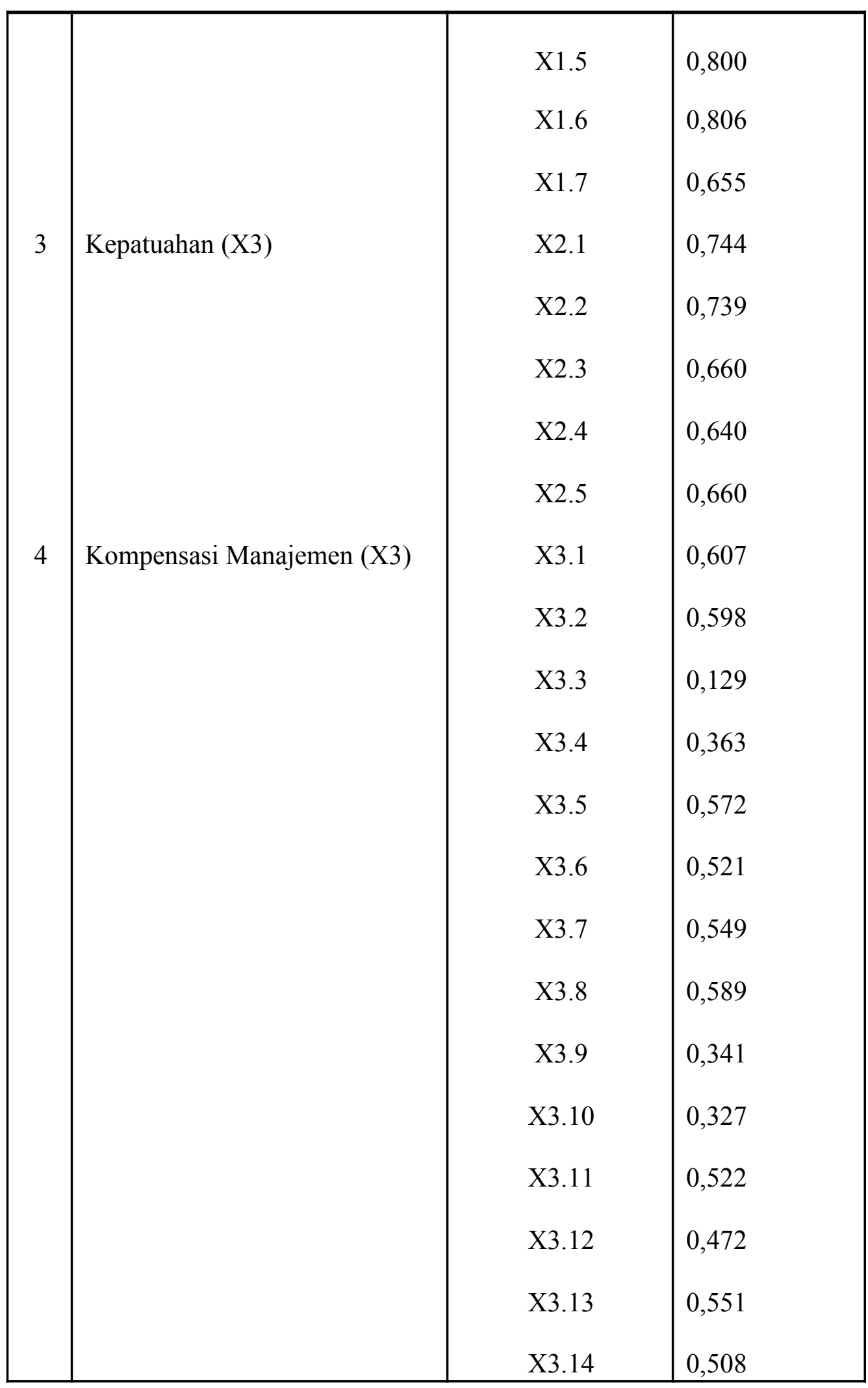

Sumber : Data Diolah, 2016 


\section{Uji Asumsi Klasik}

Uji normalitas menggunakan metode uji Kolmogrov-Smirnov yang menunjukan hasil 0,061 dan Asymp,sig (2 tailed) 0,200 >0,05. Maka data dalam penelitian ini diketahui berdistribusi normal.Hasil dari uji multikolinearitas disajikan pada Tabel sebagai berikut:

\section{Tabel}

\section{Hasil Uji Multikolonieritas}

\begin{tabular}{|c|l|c|l|}
\hline No. & \multicolumn{1}{|c|}{ Variabel } & Tolerance & \multicolumn{1}{|c|}{ VIF } \\
\hline 1 & Pengendalian Intern (X1) & 0,911 & 1,098 \\
2 & Kepatuhan (X2) & 0,849 & 1,178 \\
3 & Kompensasi Manajemen (X3) & 0,882 & 1,133 \\
\hline
\end{tabular}

Dependent Variable : Perilaku Etis

Sumber : Data Diolah, 2016

Dari tabel dapat diketahui bahwa nilai Variance Inflaction Factor (VIF) Ketiga variabel pengendalian intern, kepatuhan, kompensasi manajemen adalah lebih kecil dari 10, dan nilai tolerance diatas 0,10 sehingga dapat disimpulkan bahwa antar variabel pengendalian intern, kepatuhan, kompensasi manajemen tidak terjadi persoalan multikolinearitas.

Gambar garafik scatter plot berikut memperlihatkan bahwa titik yang tersebar tidak membentuk pola yang jelas. Jadi, tidak terjadi heteroskedastisitas pada model regresi ini. 


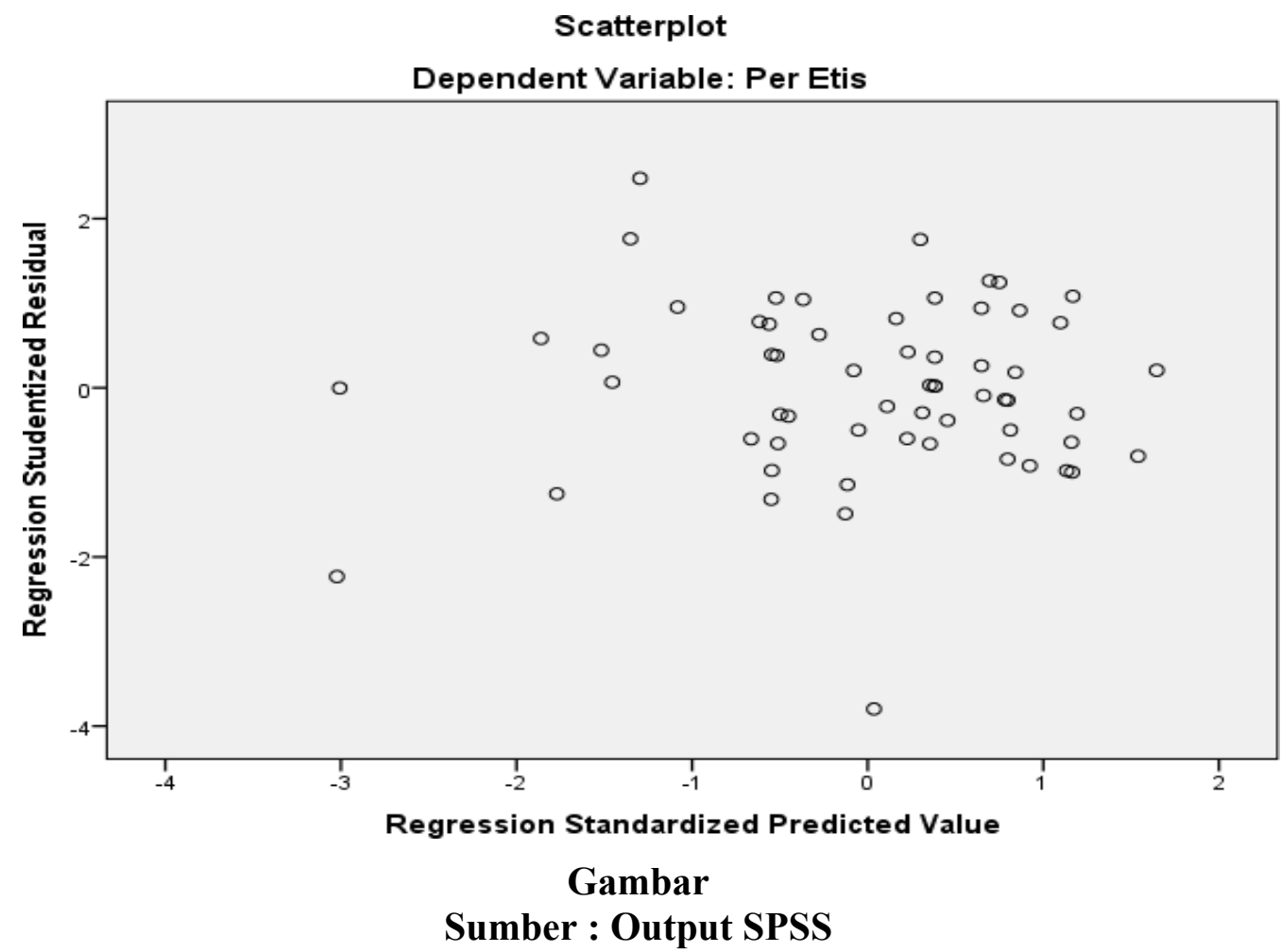

Tabel menunjukan hasil uji autokorelasi, dari tabel diketahui niali DW 1,864 lebih besar dari batas atas(du) 1,689 dan kurang dari $4-1,689$ (4-du), maka dapat disimpulkan bahwa H0 tidak bisa ditolak yang menyatakan bahwa tidak ada autokorelasi positif atau negatif dengan kata lain tidak terdapat autokorelasi. 
Tabel

Hasil Uji Autokorelasi Model Summary ${ }^{b}$

\begin{tabular}{|c|c|c|c|c|c|}
\hline Mardegic & $\left(R_{c}\right.$ & R Souare & $\begin{array}{c}\text { Adjusted R } \\
\text { Squirerern. K }\end{array}$ & $\begin{array}{l}\text { Std. Error of } \\
\text { enthenstimate }\end{array}$ & $\begin{array}{l}\text { Durbin- } \\
\text { Watson }\end{array}$ \\
\hline 4. Depe & dent V,âlab & 1e: Per , 139 &, 093 & 2,968 & 1,864 \\
\hline
\end{tabular}

Etis Sumber : Output SPSS

Tabel

Hasil Regresi Linear Berganda

Coefficients $^{\mathrm{a}}$

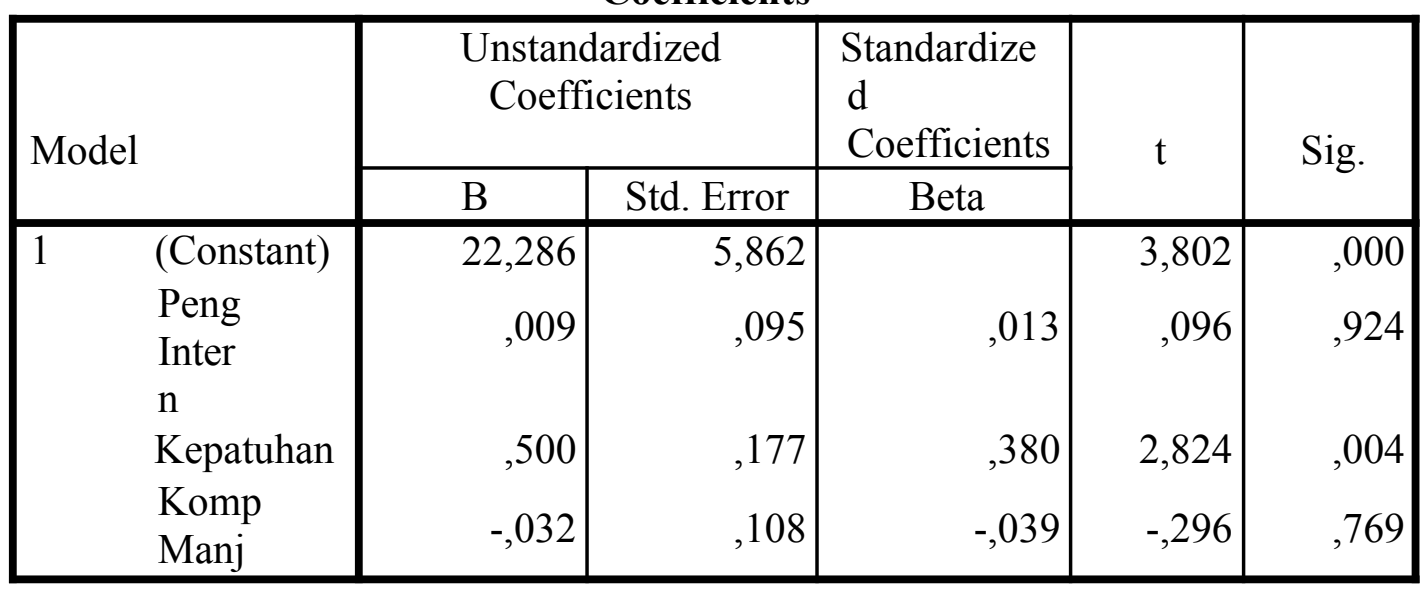

a. Dependent Variable: Per Etis

Sumber : Output SPSS

Berdasarkan tabel 5 dapat diketahui persmaan regresinya yaitu :

$\mathrm{Y}=\alpha+\beta_{1} \mathrm{X}_{1}+\beta_{2} \mathrm{X}_{2}+\beta_{3} \mathrm{X}_{3}+\mathrm{e}$

$\mathrm{Y}=22,286+0,009 \mathrm{X}_{1}+0,500 \mathrm{X}_{2}+(-0,32) \mathrm{X}_{3}+\mathrm{e}$

Tabel

Hasil Uji Hipotesis Parsial (uji t) Untuk Pengendalian Intern

Coefficients $^{\mathrm{a}}$

\begin{tabular}{|c|c|c|c|c|c|}
\hline \multirow[b]{2}{*}{ Model } & \multicolumn{2}{|c|}{$\begin{array}{l}\text { Unstandardized } \\
\text { Coefficients }\end{array}$} & \multirow{2}{*}{$\begin{array}{c}\text { Standardized } \\
\text { Coefficients }\end{array}$} & \multirow[b]{2}{*}{$\mathrm{T}$} & \multirow[b]{2}{*}{ Sig. } \\
\hline & $\mathrm{B}$ & Std. Error & & & \\
\hline $\begin{array}{ll}1 & \text { (Constant) } \\
& \text { Peng Intern }\end{array}$ & $\begin{array}{r}29,191 \\
, 080\end{array}$ & $\begin{array}{r}2,786 \\
, 096\end{array}$ & , 109 & $\begin{array}{r}10,479 \\
, 838\end{array}$ & $\begin{array}{l}, 000 \\
, 406\end{array}$ \\
\hline
\end{tabular}

a. Dependent Variable: Perilaku Etis

Sumber : Output SPSS 
Tabel

Uji Hipotesis Parsial (uji t) Untuk Kepatuhan

Coefficients $^{\mathrm{a}}$

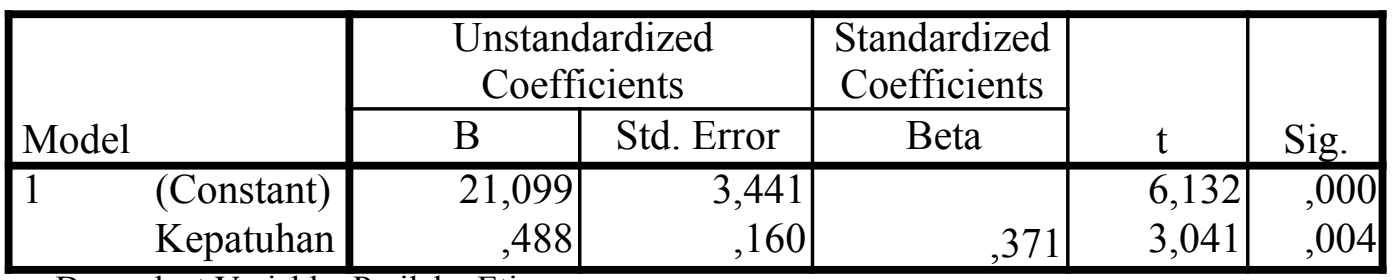

a. Dependent Variable: Perilaku Etis

Sumber : Output SPSS

Tabel

Uji Hipotesis Parsial (uji t) Untuk Kompensasi Manajemen

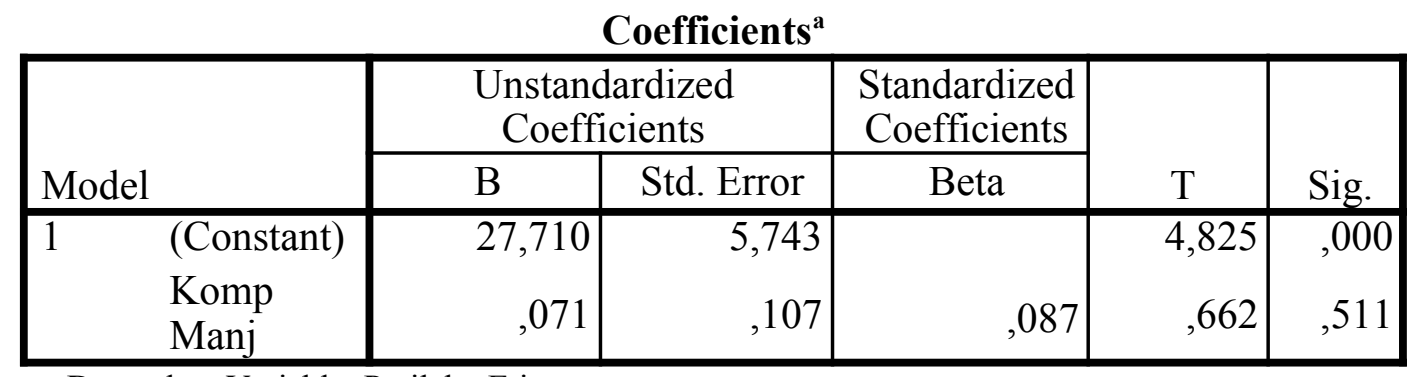

a. Dependent Variable: Perilaku Etis

Sumber : Output SPS

\section{ANALISIS DAN PEMBAHASAN}

\section{Pengaruh Pengendalian Intern $\left(\mathrm{X}_{1}\right)$ terhadap Perilaku Etis Karyawan $(Y)$.}

Berdasarkan penelitian yang telah dilakukan, hasil penelitian menunjukan bahwa pengendalian intern $\left(\mathrm{X}_{1}\right)$ secara individual tidak bepengaruh secara signifikan terhadap perilaku etis karyawan $(\mathrm{Y})$ yaitu sebesar $0,109 \times 100 \%=10,9 \%$. Nilai sig pada tabel sebesar $0,406>0,05$ ini juga mengidentifikasi bahwa variabel penegendalian intern $\left(\mathrm{X}_{1}\right)$ tidak berpengaruh secara signifikan terhadap perilaku etis karyawan (Y)Sehingga dapat ditarik kesimpulan bahwa indikator-indikator yang menjadi tolak ukur dari pengendalian intern ini tiadak dapat membuktikan pengaruhnya, adapun faktor internal yang barangkali memiliki dampak yang kuat terhadap pengendalian seperti gaya manajemen. Biasanya, sikap-sikap bawahan mencerminkan sikap yang mereka anggap sebagai sikap atasan mereka, dan sikap para atasan itu pada akhirnya berpijak pada apa yang menjadi sikap CEO.

Seberapa besar pengendalian intern yang ditetapkan jika gaya kepemimpian manajer dirasa tidak sejalan maka itu tidak akan mempengaruhi perilaku etis seorang karyawan. Hasil penelitian ini sejalan dengan penelitian yang dilakukan oleh Ruth Patricia (2012) yang menyatakan bahwa pengendalian intern baik secara simultan maupun parsial tidak berpengaruh signifikan terhadap perilaku etis karyawan. Hasil penelitian ini tidak sejalan 
dengan penelitian yang dilakukan oleh Hesti (2012) yang menyatakan bahwa pengendalian intern berpengaruh terhadap perilaku etis karyawan.

\section{Pengaruh Kepatuhan $\left(\mathrm{X}_{2}\right)$ terhadap Perilaku Etis Karyawan $(\mathrm{Y})$.}

Hasil peneliian mendukung hipotesa ke dua bahwa variabel kepatuhan $\left(\mathrm{X}_{2}\right)$ berpengaruh positif dan signifikan terhadap perilaku etis karyawan $(\mathrm{Y})$ dengan nilai sebesar $0,371 \times 100 \%=37,1 \%$, nilai sig pada tabel sebesar $0,004<0,05$ ini juga mengidentifikasi bahwa variabel kepatuhan $\left(\mathrm{X}_{2}\right)$ berpengaruh secara signifikan terhadap perilaku etis karyawan (Y). Hasil penelitian ini medukung teori yang dikemukakan oleh Roberts et.al dalam Arifiyani (2012) yang berpendapat bahwa cara profesi diorganisir, melalui antara lain kode etik, dan ketaatan atas aturan akuntansi, akan memberikan pengaruh serta mengendalikan perilaku manajemen perusahaan. Dipatuhinya aturan dan kode etik oleh karyawan akan meningkatkan perilaku etis dalam suatu perusahaan. Penelitian ini sejalan dengan penelitian Siti Aisyah (2010) yang menyatakan bahwa kepatuhan berpengaruh terhadap perilaku etis karyawan. Hasil penelitian ini tidak sejalan dengan penelitian yang dilakukan oleh Ruth Patricia (2010) yang menyatakan bahwa kepatuhan tidak berpengaruh terhadap perilaku etis karyawan.

\section{Pengaruh Kompensasi Manajemen $\left(\mathbf{X}_{3}\right)$ terhadap Perilaku Etis Karyawan $(\mathbf{Y})$.}

Berdasarkan penelitian yang telah dilakukan, hasil penelitian menunjukan bahwa kompensasi manajemen $\left(\mathrm{X}_{3}\right)$ secara individual tidak bepengaruh secara signifikan terhadap perilaku etis karyawan (Y) yaitu sebesar $0,087 \times 100 \%=8,7 \%$. Nilai sig pada tabel sebesar $0,511>0,05$ ini juga mengidentifikasi bahwa variabel kompensasi manajemen $\left(\mathrm{X}_{3}\right)$ tidak berpengaruh secara signifikan terhadap perilaku etis karyawan (Y). Ini dapat ditarik kesimpulan bahwa seberapa besarnya kompensasi yang diberikan oleh manajemen tidak mempengaruhi sifat dasar manusia yang tidak pernah merasa cukup, moralitas juga dapat mempengaruhi perilaku seseorang, karena tingkat senioritas yang dirasa memiliki hak untuk menentukan besarnya kompensasi yang harus diterimanya menyebabkan perilaku seseorang sewenang-wenang terhadap seorang yang lain. Penelitian ini sejalan dengan penelitian Ruth Patricia (2012) yang menyatakan bahwa sistem kompensasi tidak memiliki pengaruh signifikan terhadap perilaku etis karyawan. Hasil penelitian ini berbeda dengan penelitian yang dilakukan oleh Hesti (2012) yang menyatakan bahwa kompensasi manajemen memiliki pengaruh terhadap perilaku etis karyawan.

\section{KESIMPULAN DAN SARAN}

Berdasarkan analisa dapat disimpulkan hal-hal sebagai berikut Tidak ada pengaruh positif yang signifikan antara pengendalian intern terhadap perilaku etis karyawan. Ada pengaruh positif dan signifikan antara kepatuhan terhadap perilaku etis karyawan.Tidak ada pengaruh positif dan signifikan antara kompensasi manajemen terhadap perilaku etis karyawan.

Berdasarkan hasil pembahasan dapat disampaikan saran sebagai berikut Untuk PT Enseval Putera Megatrading Tbk Pusat diharapkan dapat memperbaiki pengendalian intern perusahaan, hal ini tidak hanya berlaku untuk kantor pusat tetapi semua cabang yang berada dibawahnya, Jika PT Enseval Putera Megatrading Tbk ingin memperbaiki pengendalian intern diharapkan tidak hanya faktor-faktor yang berkenaan dengan pengendalian operasional atau teknis saja tetapi fakto-faktor internal lain yang terindikasi seperti gaya kepemimpinan 
juga perlu diperhatikan karena seberapa besarpun kendali yang telah dibuat tetapi sikap pimpinan tidak mendukung jalannya pengendalian tersebut maka perilaku seorang karyawan tidak akan sejalan dengan yang diharapkan perusahaan untuk bertindak etis. Dan bagi peneliti selanjutnya diharapkan dapat menambah objek penelitiannya sehingga dapat dilihat gambaran yang mendekati kondisi sebenarnya.

\section{DAFTAR PUSTAKA}

Arens, Alvin A. et al. (2008). Auditing Pendekatan Terpadu, Salemba Empat, Jakarta.

Mardi, (2011). Sistem Informasi Akuntasi, Ghalia Indonesia, Bogor.

Mutiara S.Panggabean, (2004). Manajemen Sumber Daya Manusia, Edisi 2, Ghalia Indonesia, Jakarta.

Hesti Arlich Arifiyani. 2012, Pengaruh Pengendalian Intern, Kepatuhan Dan Kompensasi Manajemen Terhadap Perilaku Etis Karyawan, Jurnal Nominal, Volume I, No I Tahun 2012.

Imam Ghozali. 2013, Aplikasi Analisis Multivariate dengan Program IBM SPSS 21 Update PLS Regresi,Badan Penerbit Universitas Diponegoro, Semarang

John M Ivanncevich et.al (2009). Perilaku dan Manjemen Organisasi Edisi 7 Jilid 2, Erlangga, Jakarta.

Sjafri Mangkuprawira (2011). Manajemen Sumber Daya Manusia Strategik, Ghalia Indonesia, Bogor.

Ricky Griffin dan Ronald J. Ebert. (2006). Bisnis Edisi Kedelapan, Erlangga, Jakarta.

Sukrisno Agoes dan Jan Hoesada. (2009). Bunga Rampai Auditing, Salemba Empat, Jakarta.

Thomas Sumarsan. (2010). Sistem Pengendalian Manajemen,Indeks, Jakarta.

V. Wiratna Sujarweni. (2015). SPSS Untuk Penelitian. Pustaka Baru Press, Yogyakarta.

Valery G Kumaat. (2011). Internal Audit, Erlangga, Jakarta.

Siti Al Fajar dan Tri Heru. (2015). Manajemen Sumberdaya Manusia. Unit Penerbit dan Percetakan STIM YKPN, Yogyakarta.

Krismiaji. (2010). Sistem Informasi Akuntansi Edisi 3. Unit Penerbit dan Percetakan STIM YKPN, Yogyakarta.

Dasaratha V.Rama dan Federick L.Jones. (2009). Sistem Informasi Akuntansi Buku 1. Salemba Empat, Jakarta.

Sukrisno Agoes. (2012). Auditing Petunjuk Praktis Pemeriksaan Akuntan oleh Akuntan Publik. Salemba Empat, Jakarta. 